\title{
In a double-blind, randomized and placebo-controlled trial, adjuvant memantine improved symptoms in inpatients suffering from refractory obsessive-compulsive disorders (OCD)
}

\author{
Mohammad Haghighi • Leila Jahangard • \\ Hamid Mohammad-Beigi • Hafez Bajoghli • \\ Hassan Hafezian • Alireza Rahimi • Hamid Afshar • \\ Edith Holsboer-Trachsler • Serge Brand
}

Received: 19 January 2013 / Accepted: 5 March 2013 /Published online: 23 March 2013

(C) Springer-Verlag Berlin Heidelberg 2013

\begin{abstract}
Background There is growing evidence that memantine, a noncompetitive $N$-methyl-D-aspartate receptor antagonist, may be applied as an add-on in treating patients suffering from obsessive-compulsive disorders (OCD). The aim of the present study was therefore to assess the effect of adjuvant memantine in a double-blind, randomized, and placebo-controlled study of the treatment of patients suffering from OCD.

Method A total of 40 inpatients (32 females ( $80 \%$ ); mean age $=31.25$ years) suffering from OCD were randomly assigned to a treatment (administration of memantine) or a control group (placebo). Treatment lasted for 12 consecutive weeks. All patients were treated with selective serotonin reuptake inhibitors or clomipramine. Patients completed the
\end{abstract}

M. Haghighi $\cdot$ L. Jahangard $\cdot$ H. Hafezian $\cdot$ A. Rahimi

Research Center for Behavioral Disorders and Substances Abuse,

Hamadan University of Medical Sciences, Hamadan, Iran

H. Mohammad-Beigi $\cdot$ H. Afshar

Isfahan Psychosomatic Research Center, Isfahan University of

Medical Sciences, Isfahan, Iran

H. Bajoghli

Psychiatry and Psychology Research Center (PPRC), Roozbeh

Hospital, Tehran University of Medical Sciences, Tehran, Iran

E. Holsboer-Trachsler $(\bowtie) \cdot S$. Brand

Center for Affective, Stress and Sleep Disorders (ZASS),

Psychiatric Hospital of the University of Basel,

Wilhelm Klein-Strasse 27,

4012 Basel, Switzerland

e-mail: edith.holsboer@upkbs.ch
Yale-Brown Obsessive Compulsive Scale four times. Experts' ratings consisted in clinical global impression (clinical global impressions (CGI), illness severity and illness improvement; two to three times). Liver enzymes SGOT and SGPT were also assessed (twice).

Results Of the 40 inpatients approached, 29 completed the 12 consecutive weeks of the study. Of the 11 dropouts, 6 were in the target group and five in the control group. Symptoms significantly decreased across the period of the study, but particularly in the treatment compared with the control group (significant time $\times$ group interaction). Illness severity (CGI severity) also significantly decreased over time but more so in the treatment than in the control group (significant time $\times$ group interaction). Illness improvements (CGI improvements) were not significant.

Conclusions The pattern of results from the present doubleblind, randomized, and placebo-controlled study for the treatment of patients suffering from OCD suggests that adjuvant memantine does significantly and favorably impact on OCD.

Keywords Obsessive-compulsive disorder · Memantine · SSRIs $\cdot$ Double-blind trial $\cdot$ Placebo $\cdot$ Y-BOCS

\section{Introduction}

Worldwide, 1 to $3 \%$ of the population suffers from obsessive-compulsive disorders (OCD) (Kessler et al. 2005; Ruscio et al. 2010; Karno et al. 1988). Symptoms of OCD include persistent intrusive thoughts (obsessions), repetitive 
and ritualistic behaviors (compulsions), and excessive anxiety (Diagnostic and Statistical Manual of Mental Disorders 4th edition, text revision (DSM-IV-TR), APA 2000). Suffering from OCD is associated with dramatically decreased quality of life and increased risk of deteriorated social interactions and loss of employment, accompanied therefore with a high risk of disability and morbidity (Hollander 1996).

Treatment of OCD is via psychopharmacological and psychotherapeutic interventions. Cognitive-behavioral therapy is as effective as psychopharmacological interventions (Franklin and Foa 2011), though patients suffering from OCD are generally treated psychopharmacologically, and, specifically, with selective serotonin re-uptake inhibitors (SSRIs) and clomipramine, a tri-cyclic antidepressant (cf. $\mathrm{Wu}$ et al. 2012). Both psychopharmacological and psychotherapeutic interventions are successful in 40 to $70 \%$ of cases (Foa et al. 2005; Swedo and Snider 2004), though residual symptoms without full remission are often observed (Ackerman and Greenland 2002; Mataix-Cols et al. 2002), again increasing the risk for disability and morbidity (Hollander 1996).

Results from twin studies suggest a genetic basis to OCD (Hanna et al. 2005; Hettema et al. 2001; van Grootheest et al. 2005), with heritability estimates for OCD symptoms in children between 45 and $65 \%$ (van Grootheest et al. 2005). Additionally, a growing body of evidence has shown that changes in glutamate levels and distribution seem to be key to the development and maintenance of OCD symptoms (see Wu et al. 2012; Ghaleiha et al. 2013; Stewart et al. 2010 for extensive overview). That is to say, disruption to glutamatergic transmission, the main excitatory transmitter in the brain, has been observed both in human and animal studies as a key factor in production of OCD symptoms. Consequently, a search for substances indirectly regulating glutamate receptors, for example, memantine, a noncompetitive $N$-methyl-D-aspartate (NMDA) receptor antagonist, has become the focus of research in the psychopharmacological treatment of OCD (Afshar et al. 2012; McGrath et al. 2000; Wu et al. 2012). Memantine is a nonncompetitive NMDA receptor antagonist reducing glutamatergic excitotoxicity and thus protecting against the excitotoxic destruction of cholinergic neurons (cf. Pasquini and Biondi 2006). Poyurovsky et al. (2005) reported the first successful treatment with memantine augmentation in a single case study while Pascquini and Biondi (2006) reported two cases of patients suffering from OCD, with and without success with memantine augmentation. Hezel et al. (2009) reported an effective treatment of a 15 years old girl suffering from severe OCD with memantine augmentation. Stewart et al. (2010) applied a single-blind case-control study to exploring the influence of memantine augmentation in 38 out-patients suffering from OCD; to our knowledge, Stewart et al. (2010) were among the first to demonstrate the symptom improving effects of memantine augmentations in patients suffering from OCD while performing a single-blind case-control study. Most recently, Ghaleiha et al. (2013) were also able to prove, in a randomized, double-blind, placebo-controlled study, that the application of memantine add-on was significantly associated with improved short-term outcomes in patients suffering from moderate to severe OCD. Patients were about 37 years old, and the study lasted for eight consecutive weeks.

The aim of the present randomized, double-blind, and placebo-controlled study was to further prove the effectiveness of memantine add-on in the treatment of patients suffering from OCD and in this case around 31 years of age, and, unlike the study by Ghaleiha et al. (2013) in which treatment was for eight consecutive weeks, with a period of observation of 12 weeks.

Following Stewart et al. (2010) and Ghaleiha et al. (2013), we hypothesized that memantine add-on in patients suffering from severe OCD would be associated with significant symptom improvements.

\section{Method}

Study design and randomization

The present study was a 12-week, randomized, double-blind, placebo-controlled clinical trial. Patients suffering from OCD were recruited between September 2009 and September 2010 in the Farshchian Hospital of Hamadan (Iran). Prior to randomization, a total of 40 boxes were prepared and numbered from 1 to 40; of these boxes, 20 contained memantine tablets (verum) and 20 contained placebo. Staff responsible for packaging and preparation of the boxes was not further involved in the study. To number the boxes, randomization was achieved via a computerized random number generator. Next, 40 raffle tickets were numbered from 1 to 40 , put in a ballot box and stirred. At the start of the study, patients drew a raffle ticket and were assigned the box with the matching number. Patients thus received either verum (memantine $5-10 \mathrm{mg} /$ day) or placebo $(5-10 \mathrm{mg} /$ day). Neither patients nor study nurses and study physicians were informed of group assignments. Verum and placebo were given as tablets with identical shape and color, and the packaging of both compounds was likewise identical. One week before starting the study and throughout the study, patients were treated with a standard SSRI or clomipramine at therapeutic dosages for at least 12 consecutive weeks.

Sample

A total of 40 inpatients suffering from OCD (32 females ( $80 \%$ ); mean age, $\mathrm{M}=31.25, \mathrm{SD}=5.06)$ were approached and diagnosed according the Diagnostic and Statistical 
Manual of Mental Disorders 4th edition, text revision (DSM-IV-TR) criteria (American Psychiatric Association 2000). Patients were fully informed about the study aims and procedure, and about the confidential nature of data selection and data handling, and gave their written informed consent. The study took place in the psychiatric ward of the Research Center for Behavioral Disorders and Substances Abuse (Frashchian Hospital; Hamadan University of Medical Sciences, Hamadan, Iran). The local ethics committee approved the study, and the entire study was performed in accordance with the ethical standards laid down in the Declaration of Helsinki. ${ }^{1}$

\section{Inclusion criteria}

Patients were enrolled in the study if the following inclusion criteria were met: (1) diagnosis by a psychiatrist of current OCD according to the DSM-IV-TR (American Psychiatric Association 2000). (2) Yale-Brown Obsessive Compulsive Scale (Y-BOCS) score of 21 points or higher (see below). (3) No comorbid psychiatric disorders. (4) No systemic disorders such as diabetes, hypertension, hyper- or hypothyroidism. (5) No alcohol and other drug use. (6) Age between 18 and 40 years. (7) Medication 1 week prior to the beginning of the study (and continued throughout the study) of an SSRI (e.g., escitalopram, $10 \mathrm{mg} /$ day; citalopram, 30$50 \mathrm{mg} /$ day) or clomipramine (100-175 mg/day) at therapeutic dosages for at least 12 consecutive weeks (see also Table 1).

\section{Exclusion criteria}

Patients were not enrolled in the study if: (1) the abovementioned inclusion criteria were not met; (2) female participants were pregnant or breast-feeding or intended to become pregnant during the period of the study; (3) there was a history of memantine use. Patients were removed from the study if: (4) adverse effects were reported or observed; (5) the liver enzymes SGOT and SGPT increased more than threefold compared with baseline levels; and (6) patients indicated to withdraw from the study. ${ }^{2}$

Of the 40 inpatients approached, 29 completed the study; of the 11 dropouts (six in the target group and five in the control group), 9 patients (five in the target and four in the control group) withdrew from the study within the first

\footnotetext{
${ }^{1}$ The clinical trial number is: IRCT138712141743N1; www.irct.ir.

${ }^{2}$ In the latter case, in strict accordance with the declaration of Helsinki, patients were free to withdraw from the study without any further justification or explanation. Moreover, they were assured that withdrawing from the study without any further justification was in no way associated with any disadvantages.
}

2 weeks without further justification and 2 (one patient for each group) reported side-effects between the second and eighth weeks (light-headedness and vertigo ${ }^{3}$ ).

Descriptive and statistical comparisons of the target and control groups are reported in Table 1. At baseline, target and control groups did not differ with respect to gender, medication (SSRI or clomipramine), age, or symptom severity (Y-BOCS; see below).

Tools

Assessing OCD with the Y-BOCS

The Y-BOCS (Goodman et al. 1989) consists of ten items and answers are given on 5-point Likert scales ranging from 0 (lowest severity) to 4 (highest severity), with higher sum scores reflecting more severe OCD (Cronbach's alpha $=0.89$ ).

The Y-BOCS was completed four times; at the beginning of the study, after 4,8 , and 12 weeks, that is, at the end of the study.

\section{Assessing changes in illness severity and improvement}

Illness severity was assessed with the clinical global impressions (CGI; Guy 1976). This consists of one item asking how mentally ill a patient is currently. Answers are given on a 7-point Likert rating scale ranging from 1 (normal; not at all ill) to 7 (among the most extremely ill patients), a higher score therefore reflecting greater illness severity. Illness severity was assessed three times; after 4 and 8 weeks, and after 12 weeks, that is, at the end of the study.

Treatment improvement was likewise assessed with the CGI. The item asks about global improvement, and answers are given on a 7-point Likert rating scale ranging from 1 (very much improved) to 7 (very much worse), a higher score thus reflecting greater deterioration in condition. Illness improvement was assessed two times; after 8 and 12 weeks, that is, at the end of the study.

Statistical analyses

Demographic and symptom characteristics were compared at baseline between the target and control group with a Chisquare test and with single $t$ tests. A series of ANOVAs for repeated measures was performed with the factors Time (4 time points for Y-BOCS scores; 3 time points for CGI severity scores, and 2 time points for CGI improvement

\footnotetext{
${ }^{3}$ Once a week, patients received a list indicating possible side-effects due to adjuvant medication (answers; yes/no). The list was based on the Joint Formulary Committee (2004) and comprised the following side-effects: confusion, dizziness, drowsiness, headache, insomnia, agitation and/or hallucinations, vomiting, light-headedness, vertigo, and anxiety.
} 
Table 1 Descriptive and statistical overview of sample characteristics (age, gender, symptom severity, and duration of illness) at baseline between the target group (memantine) and control group (placebo)

\begin{tabular}{|c|c|c|c|c|c|}
\hline & \multicolumn{2}{|l|}{ Groups } & \multicolumn{3}{|c|}{ Statistics } \\
\hline & 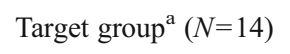 & Control group $^{\mathrm{b}}(N=15)$ & $t(27)$ & $\chi^{2}(\mathrm{~N}=29, d f=1)$ & $p$ \\
\hline Age (years; mean and standard deviation) & $30.78(6.00)$ & $31.60(5.09)$ & 0.39 & & 0.69 \\
\hline Gender (m/f) & $2 / 12$ & $4 / 11$ & & 0.67 & 0.41 \\
\hline Medication (SSRI/clomipramine) & $11 / 3$ & $11 / 4$ & & 0.11 & 0.71 \\
\hline Duration of illness (years) & $4.05(1.99)$ & $3.75(1.45)$ & 0.92 & & 0.36 \\
\hline Y-BOCS at baseline (M, SD) & $28.86(4.87)$ & $28.13(3.48)$ & 0.46 & & 0.65 \\
\hline
\end{tabular}

Description and statistics only for study completers $(N=29)$

Y-BOCS Yale-Brown Obsessive Compulsive Scale

${ }^{\mathrm{a}}$ With memantine add-on

${ }^{\mathrm{b}}$ Placebo

scores) and group (memantine vs. placebo), and the dependent variables Y-BOCS scores, CGI severity scores, and CGI improvement scores. Where appropriate, post hoc tests with the Bonferroni-Holm correction for $p$ values were used, applying single $t$ tests. To compensate for any deviations from sphericity, statistical tests were performed using Greenhouse-Geisser corrected degrees of freedom, though throughout the paper the original degrees of freedom are reported with the relevant Greenhouse-Geisser epsilon value $(\varepsilon)$. For ANOVAs, effect sizes were indicated with the partial eta squared $\left(\eta^{2}\right)$, with $0.059 \geq \eta^{2} \geq 0.01$ indicating small (S), $0.139 \geq \eta^{2} \geq 0.06$ indicating medium (M), and $\eta^{2} \geq 0.14$ indicating large (L) effect sizes (Cohen 1988).

Based on Pallanti and Quercioli (2006), the following categorizations of treatment response were calculated, based on the percentage of the Y-BOCS score reduction. Pallanti and Quercioli (2006) proposed a threshold of $35 \%$ or more in Y-BOCS reduction for "full response." 25-35\% for "partial response," and less than $25 \%$ for "no response."

The level of significance was set at $p \leq 0.05$, and all statistics were processed using SPSS ${ }^{\circledR} 19.0$ for Apple McIntosh ${ }^{\circledR}$.

\section{Results}

Changes in OCD symptoms (Y-BOCS scores)

Table 2 gives the descriptive and statistical overview for the Y-BOCS scores over four time points and separately for the target and the control groups.

Y-BOCS scores decreased significantly over time; YBOCS scores did not differ between the two groups. The time by group interaction showed that Y-BOCS scores significantly decreased over time in the target as compared with the control group.
Considering the groups separately, single post hoc analyses with Bonferroni-Holm corrections for p-values showed that in the control group YBOCS values at the first time point differed significantly from those at the third and fourth time points. For the target group, no difference was observed between the YBOCS-values at the first and the second time points; YBOCS values at the second time point did differ significantly from the third and fourth time points, and those at the third time point did significantly differ from the fourth time point. Post hoc analyses suggested that in the treatment group a continuous decrease could be observed (see Fig. 1)

Y-BOCS response rates (categorizations) and group allocation

Following Pallanti and Quercioli (2006), the following thresholds were calculated: $35 \%$ or more in Y-BOCS reduction for "full response," 25-35\% for "partial response," and less than $25 \%$ for "no response."

Table 3 gives the descriptive and statistical overview for the Y-BOCS categorizations over three time points and separately for the target and control groups.

As shown in Table 3, after 12 weeks of treatment, full response was significantly more likely in the target than in the control group.

\section{CGI symptom severity}

Table 4 gives the descriptive and statistical overview for the CGI symptom severity scores over 3 time points and separately for the target and control groups.

CGI severity decreased significantly over time. CGI severity did not differ between the target and the control group. The time by group interaction showed that CGI severity scores significantly decreased over time in the 
Table 2 Descriptive and statistical overview of the Yale-Brown Obsessive Compulsive Scale scores for four time points (baseline, after 4, 8, and 12 weeks (end of the study)), and separated by the target group (memantine) and control group (placebo)

\begin{tabular}{|c|c|c|c|c|c|}
\hline & \multicolumn{4}{|l|}{ Time points } & \multirow{2}{*}{$\begin{array}{l}\text { Statistics } \\
\text { ANOVAs }\end{array}$} \\
\hline & Baseline & $\begin{array}{l}\text { After } \\
4 \text { weeks }\end{array}$ & $\begin{array}{l}\text { After } \\
8 \text { weeks }\end{array}$ & $\begin{array}{l}\text { After } 12 \text { weeks (end } \\
\text { of the study) }\end{array}$ & \\
\hline $\begin{array}{l}\text { Target group } \\
\text { (memantine) }\end{array}$ & $28.86(4.87)$ & $28.78(3.98)$ & $24.65(4.25)$ & $19.57(3.76)$ & $\begin{array}{l}\text { Time: } F(3,81)=26.32, p=0.000, \eta^{2}=0.49(\mathrm{~L}) \\
\text { Group: } F(1,27)=0.21, p=0.65, \eta^{2}=0.008(\mathrm{~S})\end{array}$ \\
\hline Control group (placebo) & $28.13(3.48)$ & $26.07(5.20)$ & $26.00(2.70)$ & $23.67(3.56)$ & $\begin{array}{l}\text { Time by group interaction: } F(3,81)=6.09 \\
p=0.005, \eta^{2}=0.18(\mathrm{~L}) \\
\text { Greenhouse-Geisser epsilon value }(\varepsilon)=0.64\end{array}$ \\
\hline
\end{tabular}

target as compared with the control group. Considering the groups separately, single post hoc analyses with BonferroniHolm corrections for $p$ values showed that in both the target and the control group CGI severity at the first time point differed significantly from those at the second and third time points. Therefore, post hoc analyses suggested that irrespective of group, CGI illness severity showed a progressive decline (see Fig. 2).

\section{CGI improvements}

Table 4 also gives the descriptive and statistical overview for the CGI improvement scores over two time points and separately for the target and control groups.

CGI improvement scores did not significantly change over time or differ as between the target and the control group.

\section{Discussion}

The key findings of the present double-blind, placebocontrolled and randomized trial were that inpatients suffering from OCD improved significantly after 12 weeks with adjuvant memantine to standard SSRI or clomipramine medication as compared with patients with adjuvant placebo. The findings add to the current literature in so far as we were able to show in a double-blind, randomized, and placebo-controlled study design that adjuvant memantine reduces illness in inpatients suffering from OCD.

Following Stewart et al. (2010) and Ghaleiha et al. (2013), we expected symptom improvements in patients suffering from OCD with adjuvant memantine, relative to patients with placebo, and the data did fully support this expectation. In this regard, the present findings do support the most recent, though rather scarce data regarding OCD symptom improvements with NMDA receptor antagonists. Most importantly, while the response of patients in the placebo group, that is, in the SSRI or clomipramine monotherapy, was within the expected range (cf. Goodman et al. 1996; Pigott and Seay 1999), adjuvant memantine led to significantly more full responders (see Table 3). In this respect, the present pattern of results add to the current literature in so far as we were able to demonstrate a successful application of adjuvant memantine as an NMDA receptor antagonist with patients suffering from severe OCD.

Most importantly, as the data indicate (see Table 2; Fig. 1), significant improvements were observed in the target group only after 8 to 12 weeks, suggesting that a time lapse of at least 12 weeks may be necessary to observe marked improvement. Additionally, in contrast to Ghaleiha et al. (2013) who employed a time lapse of 8 weeks and speculated that perhaps the study period was too short to observe greater improvement in the monotherapy group, we note that in the present study after 12 weeks of treatment, no further improvements could be observed in the monotherapy group with standard SSRIs or clomipramine. As a result, based on the present pattern of results, we believe that a monotherapy with standard SSRIs or clomipramine leads to (modest) improvements within the first 8 weeks of treatment, while an add-on therapy with memantine produces increased efficacy but after 12 (or more) weeks. In this regard, unlike the results of Ghaleiha et al. (2013), we propose that adjuvant memantine not only accelerates the monotherapy response, but also affects the overall response rate.

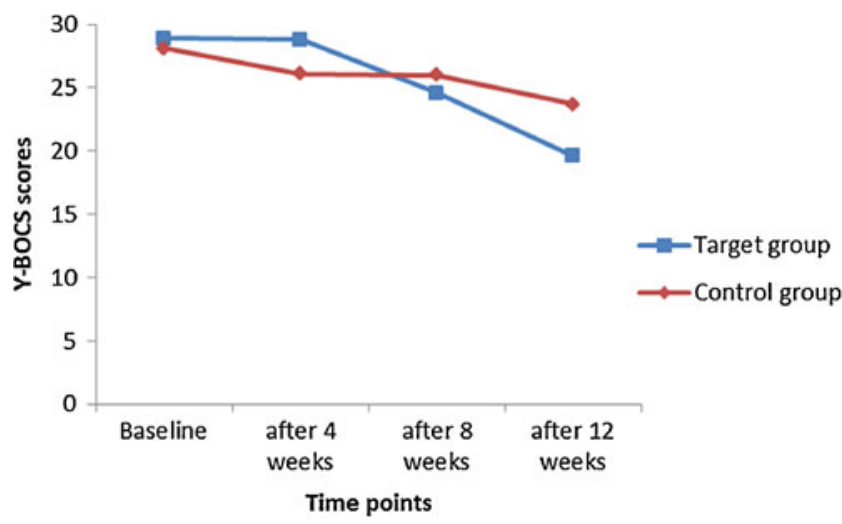

Fig. 1 Y-BOCS scores decreased over time, and above all in the target group (memantine; statistically significant time by group interaction) 
Table 3 Descriptive and inferential statistics of response rates of the Yale-Brown Obsessive Compulsive Scale (Y-BOCS), separately by target and control group

\begin{tabular}{|c|c|c|c|c|c|c|c|c|c|}
\hline & \multicolumn{3}{|c|}{ Second time point (after 4 weeks) } & \multicolumn{3}{|c|}{ Third time point (after 8 weeks) } & \multicolumn{3}{|c|}{ Fourth time point (after 12 weeks) } \\
\hline & \multicolumn{3}{|c|}{ Response } & \multicolumn{3}{|c|}{ Response } & \multicolumn{3}{|c|}{ Response } \\
\hline & Full & Partial & No & Full & Partial & No & Full & Partial & No \\
\hline Target group & 0 & 0 & 20 & 1 & 0 & 13 & 9 & 4 & 1 \\
\hline Control group & 1 & 3 & 16 & 0 & 0 & 15 & 0 & 4 & 11 \\
\hline Statistics $\chi^{2}$ & \multicolumn{3}{|c|}{$\chi^{2}(N=40, d f=2)=4.44, p=0.10$} & \multicolumn{3}{|c|}{$\chi^{2}(N=29, d f=1)=1.11, p=0.129$} & \multicolumn{3}{|c|}{$\chi^{2}(N=29, d f=2)=9.24, p=0.01$} \\
\hline
\end{tabular}

Notes: Full response $=-35 \%$ or more of Y-BOCS scores compared with baseline; partial response $=-25$ to $-34 \%$ of Y-BOCS scores compared with baseline; no response $=\leq 25 \%$ of Y-BOCS scores compared with baseline

As possible explanations for the favorable effect of memantine on patients suffering from OCD, several lines of evidence suggest an underlying glutamatergic dysfunction in the pathophysiology of OCD (cf. Rosenberg and Keshavan 1998; Saxena et al. 2001; Wu et al. 2012), with, specifically, evidence from cerebrospinal fluid studies. Chakrabarty et al. (2001) investigated cerebrospinal fluid from 21 patients suffering from OCD and 18 controls and showed that irrespective of gender, age or illness history, glutamate concentrations were significantly higher in the OCD as compared with the control group, a pattern of results replicated by the same research team with further patients and controls (Bhattacharyya et al. 2009). Moreover, whereas a balance between direct and indirect pathways in the corticostriatal-thalamocortical circuitry reflects pathophysiologically favorable processes, it is assumed that a hyperactivity of the direct pathway and/or hypoactivity of the indirect pathway leads to a disinhibition of this circuitry with

Table 4 Descriptive and statistical overview of the Clinical Global Impression Severity scores for three time points (after 4, 8, and 12 weeks (end of the study)) and of the Clinical Global Impression an ultimate effect on compulsions and obsessions (Rosenberg et al. 2000, 2004; Yücel et al. 2008). Specifically, based on proton magnetic resonance spectroscopy, Rosenberg et al. (2000), Starck et al. (2008), and Yücel et al. (2008) were able to show, in patients suffering from OCD, greater left, but not right caudate glutamatergic concentrations, as well as lower anterior cingulate cortex (ACC) glutamate concentrations. Whiteside et al. (2006) reported greater orbital frontal glutamatergic concentrations in patients with OCD as compared with controls. As an overall concept, Rosenberg et al. (2004) claimed that a possible dysregulation of glutamate within cortico-striatal circuitry with reduced glutamate in the ACC, and a glutamate overactivity in the striatum and orbitofrontal cortex may be the underlying glutamatergic process in OCD. Additionally, a broad variety of further glutamate post-synaptic signaling dysfunctions (Ting and Feng 2011) and genetic causes (see Wu et al. 2012 for extensive overview; see

Improvement scores (after 8 and 12 weeks (end of the study)) separately by the target group (memantine) and control group (placebo)
Time points

\begin{tabular}{lll}
\hline Baseline & After & After \\
& 4 weeks & 8 weeks
\end{tabular}

\section{CGI Severity}

Target group

(memantine)

Control group

(placebo)

CGI improvements

Target group

(memantine)

$\begin{array}{lll}- & - & 2.86(0.86)\end{array}$

Control group (placebo)

$\begin{array}{lll}- & 4.71(0.73) & 4.21(0.70) \\ - & 4.47(0.99) & 4.27(0.70)\end{array}$

$3.29(0.61)$

$3.87(0.64)$

After 12 weeks (end ANOVAs

of the study)
Statistics

CGI clinical global impression 


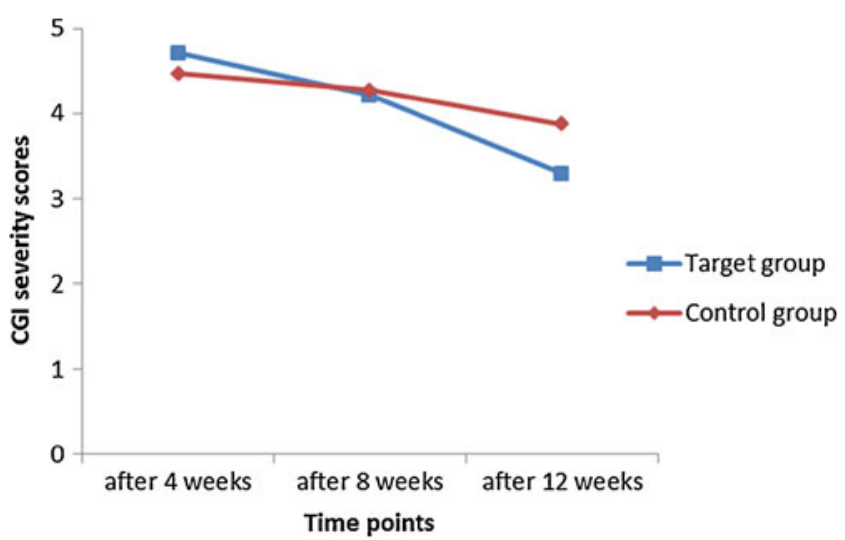

Fig. 2 Clinical global severity scores decreased significantly over time and above all in the target group (memantine)

Hanna et al. 2005; Hettema et al. 2001; van Grootheest et al. 2005 for results from twin studies) may further explain the development and maintenance of OCD.

Despite the intriguing findings, several limitations warrant against their overgeneralization. First, the sample size is rather small, though we relied more on effect size calculations which, unlike p-values, are unaffected by sample size. Second, other psychological dimensions such as depression and anxiety symptoms were not assessed, and perhaps improvements in OCD were merely a result of decreased symptoms of anxiety and depression. Third, the study design does not allow a deeper consideration of molecular processes. Fourth, likewise, the complex processes of glutamatergic regulations in various areas of the brain were neither directly, nor indirectly measured. In this respect, strictly speaking the fact that memantine as a NMDA receptor antagonist did favorably improve OCD symptoms does not directly prove that our theoretical model of the underlying mechanisms is correct. Rather, it remains possible that the present pattern of results emerged due to other though unassessed molecular, neuronal, and psychological processes (see above and below). Fifth, in this respect, glutamate receptor antagonists are related to an enhancement of 5-HT2A receptor-mediated transmission and, following Carlsson (2001), 5-HT2A agonism leads to reduced glutamatergic transmission while 5-HT receptor activation is related to a reduction of the excitatory effect of glutamate on cellular activity (cf. Saxena and Rauch 2000). As a consequence, as already outlined above, it is also conceivable that the present pattern of results is due to further, though unassessed pathophysiological processes. Sixth, only patients suffering from OCD without further comorbidities were included, leaving it unclear whether memantine add-on might be helpful for patients suffering from OCD and a concomitant broader spectrum of further psychiatric disorders. Notably, whereas it is usual to sample from comorbidity-free populations for highly standardized clinical trials, such patients are the exception rather than the rule within clinical everyday life. Seventh, the sample consisted of patients suffering from severe OCD for the first time in their lives, and it remains unclear to what extent memantine add-on might also be helpful for patients suffering from therapy-resistant and refractory OCD. Eighth, patients had sociotherapeutic events and (psychotherapeutic) contact with psychologists, psychiatrists and hospital nurses though, given that no data were gathered on these aspects, it remains unclear to what extent these sociotherapeutic events and (psychotherapeutic) contact may have favorably influenced the course of illness. However, irrespective of group assignment, all patients had the same opportunities to benefit from sociotherapeutic events and (psychotherapeutic) contacts, and therefore, it seems highly unlikely that data were systematically biased. Ninth, we note that after 8 of the 12 weeks, 11 of the 40 patients had dropped out of the study for different reasons. Therefore, the present findings should be interpreted in the light of the observed attrition rate. Last, no insight into cognitive-emotional processes was gained, leaving it uncertain to what extent psychopharmacological treatment led to new insights and modified behavior for coping with symptoms of OCD. Further doubleblind, randomized, and placebo-controlled studies on OCD might include patients suffering from refractory OCD and with additional comorbidities, as well as assessing symptoms of depression and anxiety and, for instance, cognitiveemotional processes.

\section{Conclusions}

Data from the present randomized, double-blind, and placebo-controlled study suggest that an add-on of memantine, a noncompetitive NMDA antagonist, does improve the symptoms of patients suffering from severe OCD.

Conflict of interest All authors declare no conflicts of interest; the entire study was performed without external funding

\section{References}

Ackerman DL, Greenland S (2002) Multivariate meta-analysis of controlled drug studies for obsessive-compulsive disorder. J Clin Psychopharmacol 22:309-317

Afshar H, Roohafza H, Mohammad-Beigi H, Haghighi M, Jahangard L, Shokouh P, Sadeghi M, Hafezian H (2012) $N$-acetylcysteine add-on treatment in refractory obsessive-compulsive disorder: a randomized, double-blind, placebo-controlled trial. J Clin Psychopharmacol 32:797-803

American Psychiatric Association (2000) Diagnostic and statistical manual of mental disorders, 4th edn. American Psychiatric Association, Washington, DC

Bhattacharyya S, Khanna S, Chakrabarty K, Mahadevan A, Christopher R, Shankar SK (2009) Anti-brain autoantibodies and altered 
excitatory neurotransmitters in obsessive-compulsive disorder. Neuropsychopharmacology 34:2489-2496

Carlsson ML (2001) On the role of prefrontal cortex glutamate for the antithetical phenomenology of obsessive compulsive disorder and attention deficit hyperactivity disorder. Prog Neuropsychopharmacol Biol Psychiatry 25:5-26

Chakrabarty K, Bhattacharyya S, Christopher R, Khanna S (2001) Glutamatergic dysfunction in OCD. Neuropsychopharmacology 30:1735-1740

Cohen J (1988) Statistical power analysis for the behavioural sciences, 2nd edn. Lawrence Erlbaum Associates, Hillsdale

Foa EB, Liebowitz MR, Kozak MJ, Davies S, Campeas R, Franklin ME, Huppert JD, Kjernisted K, Rowan V, Schmidt AB, Simpson HB, Tu X (2005) Randomized, placebo-controlled trial of exposure and ritual prevention, clomipramine, and their combination in the treatment of obsessive-compulsive disorder. Am J Psychiatry 162:151-161

Franklin ME, Foa EB (2011) Treatment of obsessive compulsive disorder. Annu Rev Clin Psychol 7:229-243

Ghaleiha A, Entezari N, Modabbernia A, Najand B, Askari N, Tabrizi M, Ashrafi M, Hajiaghaee R, Akhondzadeh S (2013) Memantine add-on in moderate to severe obsessive-compulsive disorder: randomized double-blind placebo-controlled study. J Psychiatr Res 47:175-180

Goodman WK, Price LH, Rasmussen SA, Mazure C, Delgado P, Heninger GR, Charney DS (1989) The Yale-Brown Obsessive Compulsive Scale. II. Validity. Arch Gen Psychiatry 46:10121016

Goodman WK, Kozak MJ, Liebowitz M, White KL (1996) Treatment of obsessive-compulsive disorder with fluvoxamine: a multicentre, double-blind, placebo-controlled trial. Int Clin Psychopharmacol 11:21-29

Guy W (1976) ECDEU assessment for psychopharmacology, revised edition. NIMH Publication, Rockville

Hanna GL, Himle JA, Curtis GC, Gillespie BW (2005) A family study of obsessive-compulsive disorder with pediatric probands. Am J Med Genet B Neuropsychiatr Genet 134:13-19

Hettema JM, Neale MC, Kendler KS (2001) A review and metaanalysis of the genetic epidemiology of anxiety disorders. Am J Psychiatry 158:1568-1578

Hezel DM, Beattie K, Stewart SE (2009) Memantine as an augmenting agent for severe pediatric OCD. Am J Psychiatry 166:237

Hollander E (1996) Obsessive-compulsive disorder-related disorders: the role of selective serotonergic reuptake inhibitors. Int Clin Psychopharmacol 11(suppl 5):75-87

Joint Formulary Committee (2004) British National Formulary (BNF), 47th edn. British Medical Association and the Royal Pharmaceutical Society of Great Britain, London

Karno M, Golding JM, Sorenson SB, Burnam MA (1988) The epidemiology of obsessive-compulsive disorder in five US communities. Arch Gen Psychiatry 45:1094-1099

Kessler RC, Berglund P, Demler O, Jin R, Merikangas KR, Walters EE (2005) Lifetime prevalence and age-of-onset distributions of DSM-IV disorders in the National Comorbidity Survey Replication. Arch Gen Psychiatry 62:593-602

Mataix-Cols D, Rauch SL, Baer L, Eisen JL, Shera DM, Goodman WK, Rasmussen SA, Jenike MA (2002) Symptom stability in adult obsessive-compulsive disorder: data from a naturalistic two-year follow-up study. Am J Psychiatry 159:263-268

McGrath MJ, Campbell KM, Parks CR, Burton FH (2000) Glutamatergic drugs exacerbate symptomatic behavior in a transgenic model of comorbid Tourette's syndrome and obsessive-compulsive disorder. Brain Res 877:23-30
Pallanti S, Quercioli L (2006) Treatment-refractory obsessive-compulsive disorder: methodological issues, operational definitions and therapeutic lines. Prog Neuropsychopharmacol Biol Psychiatry 30:400-412

Pasquini M, Biondi M (2006) Memantine augmentation for refractory obsessive-compulsive disorder. Prog Neuropsychopharmacol Biol Psychiatry 30:1173-1175

Pigott TA, Seay SM (1999) A review of the efficacy of selective serotonin reuptake inhibitors in obsessive-compulsive disorder. J Clin Psychiatry 60:101-106

Poyurovsky M, Weizman R, Weizman A, Koran L (2005) Memantine for treatment-resistant OCD. Am J Psychiatry 162:2191-2192

Rosenberg DR, Keshavan MS (1998) A.E. Bennett Research Award. Toward a neurodevelopmental model of obsessive-compulsive disorder. Biol Psychiatry 43:623-640

Rosenberg DR, MacMaster FP, Keshavan MS, Fitzgerald KD, Stewart CM, Moore GJ (2000) Decrease in caudate glutamatergic concentrations in pediatric obsessive-compulsive disorder patients taking paroxetine. J Am Acad Child Adolesc Psychiatry 39:1096-1103

Rosenberg DR, Mirza Y, Russell A, Tang J, Smith JM, Banerjee SP, Bhandari R, Rose M, Ivey J, Boyd C, Moore GJ (2004) Reduced anterior cingulate glutamatergic concentrations in childhood OCD and major depression versus healthy controls. J Am Acad Child Adolesc Psychiatry 43:1146-1153

Ruscio AM, Stein DJ, Chiu WT, Kessler RC (2010) The epidemiology of obsessive-compulsive disorder in the National Comorbidity Survey Replication. Mol Psychiatry 15:53-63

Saxena S, Rauch SL (2000) Functional neuroimaging and the neuroanatomy of obsessive-compulsive disorder. Psychiatr Clin North Am 23:563-586

Saxena S, Bota RG, Brody AL (2001) Brain-behavior relationships in obsessive-compulsive disorder. Semin Clin Neuropsychiatry 6:82-101

Starck G, Ljungberg M, Nilsson M, Jönsson L, Lundberg S, Ivarsson T, Ribbelin S, Ekholm S, Carlsson A, ForssellAronsson E, Carlsson ML (2008) A 1H magnetic resonance spectroscopy study in adults with obsessive compulsive disorder: relationship between metabolite concentrations and symptom severity. J Neural Transm 115:1051-1062

Stewart SE, Jenike EA, Hezel DM, Stack DE, Dodman NH, Shuster L, Jenike MA (2010) A single-blinded case-control study of memantine in severe obsessive-compulsive disorder. J Clin Psychopharmacol 30:34-39

Swedo SE, Snider LA (2004) The neurobiology and treatment of obsessive compulsive disorder. In: Nestler EJ, Charney DS (eds) Neurobiology of mental illness. Oxford University Press, New York, pp 628-638

Ting JT, Feng G (2011) Neurobiology of obsessive-compulsive disorder: insights into neural circuitry dysfunction through mouse genetics. Curr Opin Neurobiol 21:842-848

van Grootheest DS, Cath DC, Beekman AT, Boomsma DI (2005) Twin studies on obsessive-compulsive disorder: a review. Twin Res Hum Genet 8:450-458

Whiteside SP, Port JD, Deacon BJ, Abramowitz JS (2006) A magnetic resonance spectroscopy investigation of obsessive-compulsive disorder and anxiety. Psychiatry Res 146:137-147

Wu K, Hanna GL, Rosenberg DR, Arnold PD (2012) The role of glutamate signaling in the pathogenesis and treatment of obsessive-compulsive disorder. Pharmacol Biochem Behav 100:726-735

Yücel M, Wood SJ, Wellard RM, Harrison BJ, Fornito A, Pujol J, Velakoulis D, Pantelis C (2008) Anterior cingulate glutamateglutamine levels predict symptom severity in women with obsessive-compulsive disorder. Aust N Z J Psychiatry 42:467-477 